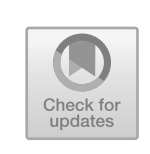

\title{
Serious Play: Inflecting the Multicultural Science Education Debate Through and for (Socratic) Dialogue
}

The purpose of this chapter is to differentially revisit the multicultural science education debate, which is a central curricular location in science education that acts as both a potential entry point and problematic gatekeeping device for Indigenous science to-come, by inflecting it with a potentially less oppositional mode of meaning-making. In short, by inspecting and inflecting the culture of this debate, this chapter engages in the cultural homework of response-ability. Within this debate, it is generally agreed upon by science educators that there is a clear moral imperative to respect students from diverse cultural backgrounds within the multicultural science education classroom. ${ }^{1}$ However, what constitutes respect and how it is enacted continues to be hotly debated; in turn, this presents itself as a rich location to unsettle science education. A significant contributing factor is how conceptions of respect are deeply intertwined with, including influenced and impacted by, considerations of "what counts" as science. This has produced two largely incommensurable positions around the inclusion of Indigenous ways-ofliving-with-Nature (e.g., ethnoscience, Indigenous knowledge systems, Indigenous science): those who contest its status as scientific knowledge and those who champion it. However, as the process of debate enacted is commonly one of opposition, there is little room for meaning made across positions. Above and beyond addressing the sources of knowledge that continue to uphold this serious debate, this chapter plays with/in the

(C) The Author(s) 2021

M. Higgins, Unsettling Responsibility in Science Education, Palgrave Studies in Educational Futures, https://doi.org/10.1007/978-3-030-61299-3_3 
debate processes as a means of opening these foreclosed spaces in science education as both form and content lead to the excluding, differing, and deferring of Indigenous science to-come.

As with most other chapters in this book, this one begins with a positional vignette meant to simultaneously introduce the topic, situate myself within the inquiry, and provide furtive glances at the concepts, questions, and curiosities to-come.

\section{Prelude to (a) Serious Play}

Because we need to "begin" some-where and some-time, let's "begin" in Thunder Bay, Ontario in February of $2009 .{ }^{2}$ During a graduate student conference (and as a graduate student), I was asked to take down a poster I was presenting minutes after I put it up. The campus-wide graduate research poster session had barely begun, as many graduate students hurried to hang their posters up. During this time, a member of the university's Faculty of Science took note of my poster as he was walking through the exhibit, seemingly on route elsewhere. However, he stopped upon seeing my poster, his face reddening as his pace accelerated. "I'm going to request that you take this poster down", he tersely demanded. Unsure as to why the request was being made, and unable to make sense of the physical cues he was exhibiting, I nervously asked, "Why?". The point of contention, he said, was the title of the poster, "Shared horizons: A dialogue between Indigenous and Western science", as well as its content below. In short, the poster highlighted my own work in crosscultural science education in which I endeavoured to juxtapose and braid Western modern science (WMS $)^{3}$ and local enactments of traditional ecological knowledge (TEK), ${ }^{4}$ namely Inuit (i.e., Indigenous) science in the circumpolar region (see Higgins, 2011, 2014). Feeling my pulse quicken, I asked him to elaborate with noticeable defensive and deliberate emphasis: "What is your issue with this?" The short of his response was that the friction was stemming from the cultural prepositions (i.e., Indigenous and Western) preceding the word science. In other words, as he told me, "there's no such thing as Indigenous science, or Western science for that matter". Agitatedly, he added, "There is only science". Reading the issue as one of not recognizing Indigenous knowledge systems as valid and productive ways of knowing nature, I too was visibly frustrated. In an attempt to recover ground, I situated the cross-cultural work within a longstanding and ongoing conversation in science education. To this, he 
retorted that this type of engagement was not happening "in science". With the tension escalating, both of us growing increasingly irritable, and neither hearing nor being heard, he repeated his demand to take down the poster. I outright refused. Our exchange ended as the faculty member went to seek out a member of the graduate student conference's organizing committee to enforce his request.

As a science educator who has worked over ten years in Indigenous communities, making space for diverse ways-of-knowing-nature was and continues to be a commitment that is both personal and political. I could not simply take down my poster. While it cannot be stated with certainty, it is likely that the science faculty member also had his own commitments that beckoned him to firmly take the position expressed. Nonetheless, there is a part of me that wishes that this exchange could have played out differently. In hindsight, and giving the faculty member benefit of the doubt, the poster could have acted as a productive conversational pivot for both involved. What if I perceived his position of science as singular and universal as something other than a potentially disrespectful "the ends justify the means" approach to morality in teaching science? What if he perceived my position of advocating for scientific pluralism as something other than "anything goes" epistemic relativism? While I would like to think that we shared a common desire for science and science education that is rigorous and empirical engages nature yet not indoctrinating through cultural imposition, it appeared as though we had implicitly agreed to disagree before said conversation could begin. If the demand for me to take down my poster had not shut down the possibility of conversation, my reaction, rebuttal, and refusal certainly did. The act of attempting conversation further entrenched our respective positions, giving the impression that a combative and antagonistic relationship was the only type we could inhabit.

While this is but one experience from my perspective, the characteristics that mark it are not isolated. Michiel van Eijck and Wolff-Michael Roth (2007) state, "one can be surprised about the fierce debate that currently shakes the foundations of science education" (pp. 927-928) and, I would add, the plurality of locations in which it is and continues to be occurring (e.g., science teacher education). Often referred to as the multicultural science education debate, ${ }^{5}$ it is not strictly isolated to a singular place but extends to plural locations that are continuously and differentially shaped by Western colonial relationships. These include 
locations: (a) where settlers remain and have become numerically dominant (e.g., New Zealand, Australia, Canada, United States, Peru, Taiwan); (b) where colonial settlers have never reached majority and/or that have undergone formal decolonizing as defined by the United Nations (e.g., India and many African nations); and (c) in which displaced diasporic communities live, whose forced migration from the lands in which their cultural identity developed is the result of colonialism past and present (e.g., descendants of chattel slaves in former British and French colonies, Hmong immigrants [formerly from Thailand] in China and the US) (Aikenhead \& Ogawa, 2007; McKinley, 2007).

At stake are notions of "what counts" as science within the context of the multicultural classroom, ${ }^{6}$ and how their entanglement, impact, and influence constitute respect and how it is enacted towards culturally diverse students. Seemingly most polarizing, and of central significance in this inquiry, is the status of TEK as scientific knowledge (or equally valid to scientific knowledge).

I would argue that the ongoing debate is not the result of poorly formulated scholarly arguments. Rather, it is a symptom of the oppositional and antagonistic modes through which the multicultural science education debate operates (see McKinley \& Stewart, 2012), such as was the case in the exchange between myself and the Faculty of Science member in the introductory vignette. For the multicultural science education debate to move towards shared meanings and understandings, it must become and remain an open process rather than a sedimented product. Open channels of communication allow for productive engagement across and between positions, rather than a protective and prohibitive form of disengagement, such as that demonstrated within the introductory vignette. As Elizabeth St. Pierre (1997) reminds us, the goal of educational research should be to both "produce different knowledge and knowledge differently" (p. 175). As such, this chapter seriously engages both within and against the norms that shape the culture of the multicultural science education debate itself by differentially (re)presenting the multicultural science education debate literature. However, the purpose here is not to produce new knowledge through the advancement of either universalist or cross-culturalist positions as is traditionally the case. Instead, I undertake, and provide tools for readers to engage the task of producing knowledge differently through a differential critical engagement with the knowledge production process that occurs within this debate in order to move towards the possibility of shared meanings. 7 


\section{Programme for (a) "Serious Play" To-Come}

Differential knowledge (re)production takes the form of (a) "serious play" as means of possibly working within and between the often "scripted" (i.e., well-established and entrenched) positions of universalist and crossculturalist in order to (re)open these foreclosed ${ }^{8}$ spaces of meaningmaking. In short, the "serious play" introduced here but expanded upon later signals an entangled conceptual apparatus comprising Socratic dialogue, Bohmian dialogue, and Derridean "play". Together, these inform the textual strategies used as well as the practices of reading advocated for. There are sharp distinctions between Socratic dialogue (i.e., Platonic form of representation of live, face-to-face discussions between two "scripted" positions), and Bohmian dialogue (i.e., the stream of meaning through which something is made in common), as well as $a$ play (i.e., theatrical drama), and Derridean play (i.e., the always already present possibility and process of (re)signification; see Derrida, 1976). However, through (a) "serious play", this very term takes a double(d) meaning in that it is both a theatrical drama (i.e., a play) engaging with serious topics as well as a serious commitment and engagement with the (re)signification (i.e., Derridean play) of the concepts and terms within. Similarly, while the format of Socratic dialogue traditionally represents discussions between two parties, it also acts as an invitation to the reader who is open to being in a Bohmian dialogue with the text to create movement of meaning between the two positions (re)presented.

The goal of this chapter is to encourage and invite "serious play", which can be read in two distinct ways. On one hand, it can be understood as a call for science educators to seriously (re)engage in the drama of foreclosed conversations around notions such as "what counts" as science and other hotly debated issues within multicultural science education. On the other hand, it can be interpreted as an invitation for science educators to engage with the always already possible play of (re)signification of these notions and the associated positions. Together, serious play calls for the dialogical movement of meaning that occurs through and during the possible play of (re)signification, be it between people, concepts, or (scripted) positions, in order to produce a different set of possible possibilities 9 emerging from discussions such as the one at the beginning of the paper as well as the one that is mimicked within the Socratic dialogue to come. 
There are four "acts" to this serious play. The first act sets the stage for the dialogue. I further expand upon the conceptually entangled notion of "serious play" through suggesting Bohmian dialogue as a means of working towards non-adversarialism, expanding upon the Derridean "play" of (re)signification, and proposing Socratic dialogue as a means of representing and producing this play. In the second "act," reading notes are provided. I describe the universalist and cross-culturalist positions participating within the Socratic dialogue and beyond, and also make suggestions for readers looking to engage in the serious play of Bohmian dialogue. In the third "act", the Socratic dialogue on multicultural science education is "played out". Herein, both universalist and cross-culturalist characters enunciate points of contention and agreement within multicultural science education (e.g., "what counts" as science) while providing a space for readers to potentially engage in differential meaning-making around these issues. The fourth and final "act" that follows the Socratic dialogue is an exploration of how knowledge is both reproduced and potentially differentially produced within the multicultural science education debate. This section also engages with recent literature that endeavours to open up multicultural science education through (re)signification of locations that threaten to foreclose the possibility of further play (i.e., those which remain unresolved and unresolvable within the debate).

\section{Act i: Setting the Stage for (a) "Serious Play" \\ From the Dialectic of Discussion to Bobmian Dialogue: An Ethic for Seriously Playing Together}

The positioning and approach enacted between the Faculty of Science member and myself within the introductory vignette could be stated to be what Janice Moulton (1983) calls the "adversary method". She characterizes it by its aim "to show that the other party is wrong, challenging them on any possible point, regardless of where the other person agrees" (p. 156). Similarly, David Bohm (1996) might qualify the above engagement between the faculty member and myself as "discussion". Discussion, having the same suffix as percussion and concussion, evokes imagery of verbal jousting in which speakers must beat, bang, and thump one another's arguments in order for one meaning to emerge victorious through the dialectic negation of the other. In order to achieve this, the discussant 
must make common their view by subsuming, sublating, or suturing over those with whom they are discussing. This "making common" is often aggressive and adversarial, the shared assumptions required to engage in conversation on common ground are rarely reached. In turn, not only is it "not a good way to convince someone who doesn't agree with you" (Moulton, 1983, p. 156) but it also breaks down the very possibility of communication (see also Latour, 2004a; Kirby, 2011). As was the case between the faculty of science member and myself, our respective refusal to consider the other's point of view (re)entrenched our respective positions. As Bohm (1996) asks, "how can you share if you are sure you have the truth and the other... [similarly] has the truth, and the truthes don't agree?" (p. 43). However, this did not mean we needed to concede our respective viewpoints. While there is always moments in which one must inhabit imposed norms within communicative spaces as a necessity, such inhabitation often requires the one conforming to allow parts of themselves to be dialectically negated. This type of subsuming, sublating, and suturing over often results in either $a$ communication (i.e., a singular imposed meaning) or a null communication (in which silences are rife with meaning; see Mazzei, 2007) but not necessarily communication as an open process of back-and-forth.

For these reasons, there is a call from scholars such as Bohm and Moulton for dialogue rather than the dialectic of discussion, a call to listen rather than strictly talk. While both dialectic and dialogue begin from an encounter in which two differing views on a similar or same topic encounter one another, their ethic of resolution differs. Dialogue's Greek roots entail through ( $d i a$, as opposed to $d i$ which would simply signal two $)^{10}$ the meaning of the word (logos). Rather than a dialectic contest between dichotomized views, dialogue acts as a stream of meaning, a process of communication in which those engaged are not concerned with defeating propositions or in which meaning is to be made common through imposition but rather a process through which meaning is being made in common. Because it is a non-adversarial model, a process through which shared meanings are made together, it does not require that the meanings interfaced together to be negated for something new to emerge. This creates space for the possibility for meaning-making positions in-between that are often lost and foreclosed in dialectic and discussion. $^{11}$

In and through dialogue, Bohm (1996) calls for "suspended action". The suspension is a call to listen that is framed as both a listening to others 
and to oneself in that the act "listening" to how we listen to others can tell us much about ourselves, including the values that frame what and how we "hear". Between the science faculty member and myself, there were diverse epistemic as well as affective cues that we could have sensed of ourselves and of the other (e.g., physical indicators of tension). They may have signalled the ways that we were being played by our respective personal assumptions. For example, if I could take my quickening pulse as an indicator of meaning on the move to partially glimpse at my then held assumption of epistemic universalism being diametrically opposed to respectful multiculturalism, perhaps I could have differently participated in the conversation. The purpose of "suspended action" is then to come to awareness, albeit partial, of how values are inflected, deferred, and deflected through our selves. It allows us to re-think the self-in-relation to the norms that shape how, who, and what we can be (see also Butler, 2005; Foucault, 1997; Mazzei, 2007; Peat, 2007). The action following a suspension period in which we consider gentle ways in which the situation can be re(con)figured, is a non-adversarial process through which shared meanings can potentially be made together.

\section{The Serious Play of (Re)Signification}

Within the introductory vignette, one of the potential issues at hand was that the very terms and conditions that shaped engagement, such as "what counts as science", were sedimented, stratified, and thus unable to move towards the shared meanings called for in Bohmian dialogue. In order for conversations around and about multicultural science education to be modes of dialogue rather than discussions, it required that the terms of engagement not be foreclosed before they are brought up. In order words, there is a need for the possibility of play. While the play that I am advocating for here is not the same as that of a child who might re-imagine a branch as wand, it is a useful metaphor with which to think as play is deeply tied to the act and possibility of (re)signification. (Re)signification is a conceptual process of un-binding and interchangeability of what something "is not" (e.g., a wand) and "is" (e.g., a stick). It is an interplay of absence and presence with respect to what is signified while retaining the signifier (Derrida, 1976). ${ }^{12}$ In turn, it allows for movement within the stream of meaning-making through the disruption and destabilization of stratified and sedimented meaning. Such decentering creates a space of meaning-making that allows for the production 
of positions in-between "present" and "absent". Play is not a complete unravelling and an undoing, but rather a critical and complicit use of that which is played with, so that new meanings can take hold (Lather, 2007; Spivak, 1993/2009). Accordingly, when that which is played with is no longer the material of children's games, "play can be serious business" (Mazzei, 2007, p. 22).

\section{Socratic Dialogue as (a) Serious Play}

For revitalizing critical conversations that mobilize meanings of what quality multicultural science education "is" and "is not", it is useful to think through a medium that works within and against the adversarial and scripted discussions operating within the field: Socratic dialogue. Plato's Socratic dialogues are often read as a representation of a live, face-to-face discussion between two scripted positions. These positions are usually in unresolved, and potentially unresolvable, opposition to one another in a manner that is not so dissimilar from the introductory vignette. However, as Richard Smith (2011) reminds us, while it could be said that Socratic dialogues are but another form of representation, they are even more so a textual invitation to think across and between the positions presented within. As Socratic dialogue is never fully captured by one definition or the other, holding these two differing readings of Socratic dialogue in tension make it an effective choice for thinking about multicultural science education. Given the ways in which the positions discussing multicultural science education are scripted, Socratic dialogue offers itself as an effective medium through which to represent a possible discussion, hence allowing for working within the script (e.g., TEK's status of "counting as science" defended or denied). Furthermore, Socratic dialogue's implicit invitation to dialogue across differently positioned concepts and commitments allows for working against the script (i.e., towards the possibility of shared meanings).

In addition to this textual invitation, Socratic dialogue provides the disruption and destabilizing through serious play required for the stream of meaning associated with dialogue. As Smith (2011) elaborates: (a) Socratic dialogues are strictly imitations, (b) imitations are always a form of play, and, accordingly, (c) Socratic dialogues are never more than (a) play. Mimesis or imitation creates "an opportunity to adopt 'alternative persona' as a mechanism for addressing difficulties" (Turnbull \& Mullins, 2007, p. 94) and playing with/in difficult positions. ${ }^{13}$ Although 
the universalist and cross-culturalist characters (re)presented within the upcoming Socratic dialogue are but imitations, seriously and respectfully engaging with them and their interplay means not turning them into caricatures of their positions. While Socratic dialogue is long known to engage in serious topics, it is a mode in which seriousness and playfulness are always in tension and inverting so that "they do not form a fixed binary" (Smith, 2011, p. 230) as they are always already enacting the play of (re)signification. In addition, as it is (a) play with serious topics, "most attempts in the dialogues to reach a definition-of courage, friendship and so on-fail resoundingly" (Smith, 2011, p. 223). This "failure" to reach fixed and (fore)closed conclusions or outcomes has much to do with play's productive prevention of foreclosure through keeping meaning on the move. Accordingly, this generates a space for meaning-making that is never fully prescriptive (i.e., meaning is not already made for the reader but rather always open to a certain degree of interpretation), and always open to further play (i.e., meaning is open to the possibility of (re)signification as the context under which it is signified differs). For this reason, Socratic dialogue acts as an invitation to the reader to engage in their own playfulness with the ideas found within, to play with serious notions that desire to be (re)produced differently.

\section{Act 2: The Programme for (A) "Serious Play": A Primer for Playing Along}

\section{Who Is Playing (or Played)?}

The Socratic dialogue intentionally plays within the period when this debate reached its peak. As such, this dialogue primarily focuses on and draws from what van Eijck and Roth (2007) refer to as "one of the landmarks" (p. 927) of multicultural science education (see also McKinley \& Stewart, 2012), ${ }^{14}$ as well as some of the pieces the symposium authors were responding to. Accordingly, the "key players" and their respective scholarship primarily informing and inspiring the universalist account are the work of William Cobern and Cathleen Loving (2001), Michael Matthews (1994), Harvey Siegel (1997, 2001), and Sherry Southerland (2000). Similarly, the cross-culturalist position which is "played out" draws on the scholarship of Bradford Lewis and Glen Aikenhead (2001), Gloria Snively and John Corsiglia (2001), as well as William Stanley and Nancy Brickhouse (1994, 2001). 
Within the field of science education, universalists are those who uphold the belief that WMS is the best, most valid, and/or powerful way of knowing the natural world. Furthermore, universalists see WMS as a knowledge-practice that is quasi-objective, quasi-neutral, and/or quasitranscendental vis-à-vis culture. On the subject, Matthews (1994) states that universalists:

... regard science as an intellectual activity whose truth-finding goal is not, in principle, affected by national, class, racial or other differences: science transcends human differences... This universalist view recognizes that while aspects of culture do influence science, nevertheless cultural considerations do not determine the truth claims of science. (p. 182)

WMS's epistemic superiority with regard to knowing nature is substantiated by WMS's ability to explain, predict, empiricize, and stabilize natural phenomena, and apply this scientific knowledge to produce technologies that are unique (e.g., airplanes, modern medicine). Because WMS can at once be framed as culturally specific and universal, universalists within the multicultural science classroom continue to deliver science education curriculum which is about enhancing students' scientific literacy by developing an appreciation, and understanding, and applications of WMS in everyday life. However, recognizing that universalism and multiculturalism are not a mutually exclusive and dichotomous, universalists endeavour to instructionally provide culturally diverse students whose opportunities to learn WMS in ways that are respectful of that diversity.

Within this Socratic dialogue, the universalist character's account and engagement is primarily inspired and informed by the aforementioned scholars who take this stance with respect to multicultural science education. Also, in keeping with the goal of "serious play", these accounts are inflected by recent scholarship that revisits the multicultural science education debate as a means of working towards shared meanings from a universalist position (e.g., Cobern \& Loving, 2008; El-Hani \& de Ferreira Bandeira, 2008; El-Hani \& Mortimer, 2007; Zeyer, 2009).

Cross-culturalists are those who take up the pluralization and proliferation of scientific perspectives, and the localization of scientific knowledge without characterizing knowledges as relativistic (see McKinley, 2007). Cross-culturalists accept and promote the idea that TEK can and should be considered "equal" to that of WMS. This does not entail treating them equal (i.e., the same) but as equally valid. Cross-culturalists work from 
the assumption that because WMS stems from the dominant, hegemonic culture, many students who are not of that culture will experience science education as a form of dominance and hegemony. This experience is, in part, rooted in the valuation of WMS through decentering and devaluing of their own cultural knowledge. As a result, cross-culturalists uniquely endeavour to reform curriculum in addition to modes of instruction. With respect to science education curriculum, there is a commitment to create space in which TEK is included and simultaneously decenters WMS (see Aikenhead \& Ogawa, 2007; Aikenhead \& Michell, 2011; LeGrange \& Aikenhead, 2016). It is important to note that what is argued for here is not a teaching of all non-Western-modern bodies of knowledge, which could result in relativism, but rather an inclusion of diverse and longstanding empirical ways-of-knowing the natural world. With respect to instruction within the multicultural classroom, the focus shifts from having students accept culturally diverse scientific notions towards developing understanding and appreciation. This often entails that crossculturalist teachers assist their students in respectfully and meaningfully navigating cultural spaces that are not their own without the requirement that students abandon whichever way-of-knowing-nature that they are further developing.

In this Socratic dialogue, the cross-culturalist account and engagement is primarily inspired and informed by the aforementioned scholars who take this stance with respect to multicultural science education. To engage in the play of (re)signification, the cross-culturalist account is also inflected by revisitations of the multicultural science education debate that works towards shared meanings from a cross-culturalist position (e.g., Alsop \& Fawcett, 2010; McKinley \& Stewart, 2012; van Eijck \& Roth, 2007).

It is important to note that while there are often internal similarities within both of these positions in terms of how they are both defined and enacted, there is also diversity. While the characters within the dialogue are $a$ universalist and $a$ cross-culturalist who are composite characters of the scholars who inspired this dialogical inquiry, there is not $a$ singular way of being either a universalist or a cross-culturalist. While we should perhaps change the terms of the conversation to account for universalisms and cross-culturalisms, it is generally the case that both universalists and cross-culturalists will internally agree on the notion that WMS is or is not the most or only valid way of knowing the natural world respectively. However, the strength of such a "what counts as science" claim 
and other interrelated claims varies greatly within both positions, as well as the degree to which one embodies such beliefs within their research and teaching practices. It could even be argued that one need not consciously or explicitly hold the belief that WMS is or is not the most or only valid approach to be a universalist or a cross-culturalist respectively but rather that any and every science educator's curriculum and pedagogy can implicitly demonstrate and convey such commitments (see Carter, 2004; McKinley, 2000; Sammel, 2009).

These normative and counter-normative values are always already circulating and inflecting the signification of what it means to be science educator. As such, it is worth highlighting here that the strict use of two characters is not an attempt to present them as the universalist and the cross-culturalist. Furthermore, even if that were the goal, the ongoing play of (re)signification makes it such that the position, even if there is an attempt to fully account for the range of diversity, is always exceeded, ruptured, and overturned. In other words, even in a more comprehensive and expansive definition of both universalist and cross-culturalist positions, there is always already someone who identifies as either but only partially fits within. Rather than attempting to engage in the impossibility of presenting an essence, this dualistic choice is made as a means of, first, working within the constraints that are posited by Socratic dialogue as a methodology. Secondly, it is an attempt to reproduce some of the particularities that occur through the adversary method. In particular, the assumption that:

the only, or at any rate, the best, way of evaluating work ... is to subject it to the strongest or most extreme opposition. And it is assumed that the best way of presenting work ... is to address it to an imagined opponent and muster all the evidence one can to support it. (Moulton, 1983, p. 153, emphasis in original)

This imagined opponent is often the most radical proponent of that which is considered the adversary. While scholars often see their own encampment as rich and diverse, through the adversary method, the opposing side often becomes a parody of itself. As a result, the imagined adversary who is addressed is often positioned in a manner that few, if any, scholars occupy. Universalists are not-so-gently cast as wholly privileging epistemic claims (through the norms of Western modernity) over moral or ethical ones, and vice versa for cross-culturalists. This creates perceived positions 
which are either strawmen or deeply untenable. If more modest positions are not more frequently discussed it is because scholars "who cannot be recast into an adversarial mold are likely to be ignored" (Moulton, 1983, p. 155). In some ways, like Socratic dialogue, the multicultural science education debate has become a scene where drama (i.e., the serious matters of "what counts" as science) and comedy (i.e., the parody-like positioning of adversaries) alternate and seep into one another.

\section{Rules for (a) Serious Play}

Serious play is not something that occurs on its own. ${ }^{15}$ Rather, the act of "playing" (i.e., (re)signification) is a process that requires both players (e.g., "readers") and played (e.g., texts). Furthermore, "playing" occurs through the movement in-between the two. Consequently, as a reader you are encouraged to engage with the Socratic dialogue in a manner that is dialogical (i.e., so that there is movement in-between your views and the views presented within the text and something is made in common through reading), rather than dialectic (i.e., so that either your views or the views presented within the text are made common through reading). Here, the practice of suspended action is significant as a lived practice of dialogue and a (partial) coming-to-awareness of what we think, as well as how what we think is produced and producible. ${ }^{16}$

Achieving dialogue through suspended action, be it between people, texts, or ideas, is not such a simple task as we often hold, and are held by, assumptions that make it difficult for us to know differently. On this, Bohm (1996) states that the assumptions we always already hold are entangled within the meaning-making process. They not only shape and are shaped by what we know (as representations), but also how we come to know (as the world presents itself to us):

... representation is not only present in thought or in imagination, but it fuses with the actual perception or experience. In other words, the representation fuses with the "presentation," so that what is "presented" (as perception) is already in large part a re-presentation. (p. 64, emphasis in original)

In other words, as difference presents itself in the world, the assumptions that frame our thought subsume what is perceived within a representation, hence producing sameness. If we seriously desire being open 
to difference, Bohm (1996) states that there is a need to "go into all the pressures that are behind our assumptions... into the process of thought bebind the assumptions, not just the assumptions themselves" (p. 9, emphasis in original). However, as Bohm (1996) states, "thought is not proprioceptive" (p. 29). In other words, thought is incapable of perceiving itself. It is impossible to simultaneously think about something and think about how we are thinking about something. Furthermore, the privileging of one is almost always at the expense of the other (see also Barad, 2007; Lather, 2007). Despite the impossibility of fully thinking about how we think, this does not mean that we are "off the hook".

Because thought is incapable of perceiving itself, Bohm (1996) suggest paying attention to the affective and embodied movements occurring alongside thought. This, he suggests, might offer a means of differentially thinking about how we think while working towards the suspension of our assumptions. As Moulton states (1983), such "reasoning has largely been ignored by [scholars] because it is different from the reasoning used to address an adversary and it is too complex and interrelated to be evaluated by counterexamples" (pp. 160-161). As such, considering that which is usually excluded from consideration in meaning-making processes can become a useful tool in producing knowledge differently.

These affective and embodied movements of thought are not only much more (self-)perceptible than thought but also hold a direct connection to thought:

Movements are taking place inside you - physical feelings - the heart beat, the blood pressure, the way you breathe, the way your body feels tense; and also the kinds of thoughts that go along with these feelings. You can observe these things, be aware of them, and their connection. (Bohm, 1996 , p. 84)

While a consideration of sensorial or affective cues on their own might not provide direct insight into our assumptions and could also be considered an act of navel-gazing, Bohm (1996) states that they are nonetheless indicators that the process of knowing is occurring. Furthermore, not only are they connected to thought but also part of thought. For Bohm (1996), thought is "part of a material process" which happens with/in "the brain, the nervous system, [and] the whole body", such that thought is not and should not be considered as disembodied and separate from affect as they are "all one system" (p. 94). Accordingly, sensorial or affective 
cues should be thought of as constitutive parts, and signals of the process of thought. Whether this process is one of knowledge production (i.e., new meaning being made of experiences or perceptions) or reproduction (i.e., new experiences or perceptions being fused over by previously held meanings) of knowledge, emotional and embodied indicators provide a rich entry point for attempting to think about how you think.

Therefore, as you read the Socratic below dialogue below, there is an explicit invitation to attempt to suspend the moments in which you would want to interject and pay attention to your feelings, both emotional (e.g., frustration) and physical (e.g., furrowing of the brow) as they become productive sites of inquiry into how we think about how we think (e.g., the systems and norms through which thought are inflected). If we take the idea that playing requires both players and that which is played, not only does a text require a reader for (re)signification, but it may be productive to think about these affective and sensorial movements as one of the ways in which the text is playing the reader.

\section{Act 3: "Two Science Educators Walk INTO A BAR": A SOCRATIC Dialogue on Multicultural Science Education}

Persons of the Dialogue: UNIVERSALIST (U); CROSSCULTURALIST (CC).

Scene: Two multicultural science educators, one a universalist, the other a cross-culturalist, meet to discuss teaching practices over a pint of their favorite form of fermentation.

$U$ : Hello [CC]. I know that in the past, we haven't always seen eye-to-eye on what multicultural science education might entail; I thought that today we could attempt to begin our dialogue from a point on which we both agree. I brought with me a definition of multicultural science education upon which we should both be able to concur:

Multicultural science education is a construct, a process, and an educational reform movement with the goal of providing equitable opportunities for culturally diverse student populations to learn quality science in schools, colleges, and universities. (Atwater \& Riley, 1993, p. 664) 
CC: Hello [U]. Great idea! This is certainly a view of multicultural science education that I can get behind. I take it this is also the case for you, having picked the definition.

$U$ : You are correct.

$C C$ : Although we may both agree on the definition, I fear that we may read, and implement the same definition differently.

$U$ : How so?

$C C$ : I believe we differ in how we might interpret what is meant by "quality science".

$U$ : In that, like Southerland (2000), I view "quality science" as "inquiry characterized by reliability on evidence and reason with the goal of understanding an objective, external, physical world" (p. 290)?

$C C$ : Yes, and that I, like Masakata Ogawa (1995), characterize science as "a rational perceiving of reality" (p. 588, emphasis in original). ${ }^{17}$ That is not to say that our respective definitions are incommensurate. However, partnering words such as reliability, evidence, and external with reason gives me the impression that there is a particular form of reason that you may be privileging through this process. Nonetheless, I am more concerned with how your definition of science is enacted within and through your teaching practices, particularly around "what counts" as science. If I may inquire, which systems of knowledge describing the physical world could be, should be, and are taught as "science" within your science classroom?

$U$ : For the most part, my science education practices revolve around canonical understandings of science. In other words, WMS is primarily what is taught in my classroom. While I do not shy away from, nor am I opposed to, teaching other scientific viewpoints and meaningmaking structures for understanding the natural world, WMS is the most effective and useful system for working towards knowing nature.

$C C$ : Is it fair here to state that the way in which you address multiculturalism in your classroom is largely instructional rather than, or in addition to being, curricular?

$U$ : Yes, that would be a fair statement.

$C C$ : Before we address instructional questions, I would like to ask you a few curricular ones.

$U$ : Go ahead.

$C C$ : Within science education curricula, the belief of WMS holding a position of scientific superiority is one that is often and simply takenfor-granted. However, this is not an accusation I am making of you. I assume that your centering of WMS is an informed choice. Could you justify this claim you make for WMS? 
$U$ : First, WMS demonstrates the properties that are at the heart of "quality science": scientific knowledge and theories that are genuinely testable, predictive, and explanatory. Secondly, this is not to say that other ways of knowing the natural world are ineffective or not of value but rather that WMS best matches the criteria I have outlined previously.

$C C$ : While I recognize the desire to make utilitarian curricular choices within educational spaces, it is also important to think about what is being maximized through these choices as well as how and why these choices are being made. My primary concern here is that how you define science and implement educationally might be at odds with "providing equitable opportunities for culturally diverse students" (Atwater \& Riley, 1993 , p. 664). In other words, taking such a stance is potentially disrespectful to students whose culture might not align with that of WMS, ${ }^{18}$ be it in the context of science education or elsewhere.

$U$ : I'm not sure I follow as to how my curricular conception and instructional delivery of science education might be inequitable or disrespectful, but I am willing to hear you out. Go ahead. Make your case.

$C C$ : Since science is dependent upon an intersection of particular experimental systems, communities of researchers, organizational modes, as well as historical circumstances, all of which contextualize the generation of scientific knowledge, would you not agree with me that science is a situated practice?

$U$ : Yes, I would have to agree.

$C C$ : Similarly, since education is linked with culture, gender, history, sociopolitical and socio-economic context, amongst other factors, would you agree that education is also a situated practice?

$U$ : Yes, go on.

$C C$ : Should it not be argued then that science education, like its two constitutive parts, science and education, also be a situated practice?

$U$ : Agreed.

$C C$ : Then, should science education, as a situated practice, not also draw upon and reflect the contexts within and through which it emerges? This might entail many different things when considering a variety of contextual elements such as the constitution of the student body. For the sake of this conversation, I would like to clarify that I am referring specifically to the inclusion and reflection of TEK, be it called ethnoscience, Indigenous science, Indigenous knowledge systems or something else altogether, to enhance students' learning within the science classroom.

$U$ : I would cautiously agree with you that science education should draw on and reflect the educational context. As I mentioned earlier, I am not opposed to teaching bodies of cultural knowledge alongside scientific 
beliefs, because teaching TEK, IWLN, ethnoscience, and other forms of culturally-specific scientific understandings can enhance students' learning by illustrating what WMS can do that which other approaches to the natural world cannot. In other words, including non-canonical understandings of science can be a way of showing that not all thoughts are equal in all contexts. The inclusion of ways of knowing nature beyond WMS in the science classroom is not something that is agreed upon by all universalists. However, I do not view the exclusion of TEK or other approaches to knowing nature as an essential practice within science education. As an aside, I would like to inquire into the criteria you are utilizing for the systems of knowledge whose inclusion you are arguing for.

$C C$ : I can certainly elaborate upon this. As you will recall, we have discussed and agreed upon earlier that science needs to be conceived as socio-culturally situated. However, this is not to say that it is only situated in this manner. As Karen Barad (2007) states, it is important "to remember that there are cultural and natural causes for [scientific] knowledge claims" (p. 40, emphasis in original). Accordingly, the ways-of-knowing-nature that I am arguing for are not only culturally situated, but also rooted in natural empiricism. Not only is TEK empirical in its engagement with one's natural environment, but it is also a longstanding, intergenerational human engagement whose knowledge traditions often span thousands of years. As such, I am arguing for a pluralism of ways-of-knowing the natural world in which both culture and nature are significant and significantly engaged factors in the development of the knowledge claims being made.

$U$ : While I do not wish to make a "slippery slope" argument, would Creationism fit here?

$C C$ : It certainly is not my intent to exclude Western ways-of-knowing the natural world that are not WMS as there are multiple forms of TEK stemming from the West. However, as I understand it, Creationists' knowledge claims about the natural world are primarily, and possibly strictly, culturally-based (i.e., around biblical scripture). As it does not meet the criteria of natural and cultural causes for knowledge claims, Creationism would not, and should not, be included with the other bodies of knowledge that "count as science". The pluralism for which I am arguing need not and should not be an "anything-goes" form of relativism.

$U$ : Thank you for the clarification.

$C C$ : It is my pleasure. Furthermore, I think you would agree with me here that the science classroom should not be a place of dogmatic education. $U$ : I do agree here. 
$C C$ : Then, if you will allow, I would like to ask further questions around your earlier statement around how, in your science education practices, you might include other bodies of scientific knowledge and compare them to WMS. In particular, I am curious as to how you might respond to the oft-enunciated claim that a WMS-centered science curriculum has been and continues to be indoctrinating when there are pluralistic perspectives with the classroom.

$U$ : Certainly, go ahead.

$C C$ : Do you believe that it is possible both to respect youth whose culture is reflected in TEK and represent that TEK in terms of contrast with, indeed in terms of deficit to, WMS? Furthermore, if WMS is maintained as the primary curricular content in light of plurality, how do you avoid the pitfalls of this becoming a form of dogmatism?

$U$ : If it is done with caution, sensitivity, and care, I believe that this comparative process can be engaged in and taught respectfully. Also, one can teach science without demanding that students change their beliefs, or denying them altogether. I recognize that historically there have been many cases in which interfacing WMS with other ways of understanding the natural world have been problematic in that they have forcefully produced totalizing discourses, cultural silencing, and marginalization. As Cobern and Loving (2001) state,

The problem is not that science dominates at what it does best: the production of highly efficacious naturalistic understanding of natural phenomena. The problem is that too often science is used to dominate the public square as if all other discourses were of lesser value. (p. 62)

I am not advocating for education that is disrespectful or impositional. The issue at hand is not the comparative work, nor the centering of WMS, but rather the educational mode through which it was done. One can engage in teaching WMS without it devolving into scientism through its unquestioned and unquestionable privileging at the expense of other forms of knowledge.

$C C$ : Would you care to elaborate on this? I do not understand how you can simultaneously respect an individual while not affording validity to their culturally-based scientific knowledges.

$U$ : While these comparisons may not hold certain cultural knowledges as equivalent to WMS, this is not to deny them validity. Rather, it acts as an explication of how these knowledges do not meet the scientific standard. This also entails that there are situations and contexts in which 
WMS is not the most appropriate form of knowledge. Furthermore, and accordingly, such comparisons do not discredit the individual learner.

$C C$ : Therefore, as I understand it, the terms we are currently discussing are not those of "what counts" as science, but rather those of what counts best, as well as when, how, and where.

$U$ : Most certainly.

CC: However, if WMS is the only way of understanding the natural world that is recognized, perceived, or privileged as "quality science" or as best meeting its criteria, would students of non-Western cultures be required to learn WMS at the expense of their culture? Furthermore, if this is not to discredit the individual learner, could this be considered a form of epistemic violence?

$U$ : As I said, this would have to be done with caution, sensitivity and care; I am not advocating for a form of science education that is inherently disrespectful. It seems that we may have diverging notions of what respect may entail in the multicultural classroom. Let us take a step back and discuss this term of engagement.

$C C$ : Certainly.

$U$ : Within a multicultural classroom, there is a clear and moral imperative to treat members of all cultures justly and with respect, correct?

$C C$ : Of course.

$U$ : Therefore, it is imperative that all students, as well as their cultures and cultural beliefs be treated with respect as well.

$C C$ : I agree with you up to here. Go on.

$U$ : However, it is important to note that respecting students, as well as their cultures does not require treating their scientific beliefs as scientific knowledge. There is nothing wrong with identifying a set of beliefs as scientifically deficient, so long as it is done in a culturally sensitive manner, of course. The goal of science education is to make students scientifically literate, not indoctrinate them through scientism.

$C C$ : You are correct in highlighting the importance of science education not simply being about teaching and upholding any belief about the natural world. As mentioned earlier, science education should certainly not become an "anything goes" form of relativism. However, this is not to say that all cultural knowledge about the natural world should simply be treated as belief. Even if the criteria for "what counts" as knowledge of the natural world is different across various cultural knowledge systems, this does not mean that TEK needs to loses its status as knowledge once it enters the science classroom. It is also worth noting that while all culturally developed systems for understanding nature are different, there are often similarities as well. For example, Gregory Cajete (1999) makes such a comparison between Indigenous 
science and WMS in stating: "Indigenous science is a broad category that includes everything from metaphysics to philosophy to various practical technologies practiced by Indigenous past and present" (p. 83). Similarly to WMS, Indigenous science "has models which are highly contextual to tribal experience, representational and focused on higher order thinking and understanding" (p. 85).

$U$ : Perhaps I should rephrase my earlier statement. I do not wish to deny diverse culturally-specific knowledge about the natural world the status of knowledge. Furthermore, the degrees of similarity are in fact worth noting as many forms of ethnoscience have rich histories of empirical naturalistic observation. However, is there not something lost in calling TEK “science?"

$C C$ : Not always, but it is certainly a possibility that is always present. When placing multiple and diverse competing claims next to one another, there always runs the risk that they become homogenous in a way that erases their diversity and distinctiveness.

$U$ : This is not only the case for TEK, but also WMS.

$C C$ : I certainly agree.

$U$ : If so, then why is calling TEK science or having it "count" as science of such importance?

$C C$ : So long as "science" continues to be used in some educational locations as a term that excludes rather than includes, there is a need to continue working within that space even if it is complicated, complex, and sometimes contradictory.

$U$ : I agree with you here that there continues to be science educators who deny the inclusion of any other way of knowing nature beyond WMS, but that is not what I am advocating for here.

$C C$ : There is, however, one complexity or complication that I would like to further discuss with you when both TEK and WMS are included within a curriculum. Here, we both agree that such juxtapositions potentially affect both TEK and WMS. However, as I see it, these processes of interaction are not always even and equal in what they produce.

$U$ : How so?

$C C$ : Without going into a longstanding history of uneven interactions between TEK and WMS, it is nonetheless worth considering the positioning of both bodies of knowledge within the science classroom. As you mentioned earlier, you believe that it is possible to treat non-Western-modern ways of knowing nature with respect while simultaneously treating them as scientifically deficient in comparison to WMS. To me, treating TEK as less valid than WMS sends a message that is not so dissimilar from treating it as invalid. While "what counts as science" 
has changed to be more inclusive, this type of valuation seems to indicate that the norms through which it comes to count remain similar, if not the same. However, perhaps I do not understand your position correctly. Would you care to elaborate upon how you come to validate scientific knowledge within the science classroom?

$U$ : Certainly. It is worth repeating here that I do not wish to deny TEK the status of knowledge about the natural world. However, this does not mean that it wholly stands up to WMS or the criteria of "quality science". If we return to our earlier and agreed upon definition of science education as providing students opportunities to learn "quality science", I think it is worth noting that quality is not something that varying or competing forms of knowing the natural world have or do not, but rather that some approaches are better than others. As Siegel (2001) asserts, "knowledge prized by WMS goes beyond the observational, in that it seeks ... theories which are testable, and which predict and explain naturalistic observations" (p. 809). These are not only qualities attributed to the knowledge but also the knowledge building process. WMS seeks "the discovery, articulation and, explanation of regularities in nature in terms of laws which are invariably universal and invariant across time and place. This is not an assumption of universalists, but rather a methodological directive of WMS" (p. 805, emphasis in original). Do note that I am not attributing perfection to WMS as there are many contexts in which it is not the most appropriate form of knowledge such as the arts and the social sciences. However, I can confidently claim that culturally-specific understandings of nature such as TEK, as Siegel (2001) states, are "less adequate as scientific understandings than those of WMS" (p. 809, emphasis in original). While culturally-specific understandings of nature share naturalistic observation as a property with WMS, they do not achieve or produce the same quality of explanatory, testable, and predictive theories around, or towards further, observation. As such, I believe that it would be a disservice to students to not teach them primarily about the system that has reached the deepest understanding of the natural world, WMS.

CC: I agree with you that not teaching students WMS would be to do them a disservice. If you will recall, I am not arguing for the exclusion of WMS but rather for an inclusion of other ways of knowing the natural world that also takes them seriously. While I cannot fault your logic for the claim of scientific superiority that you are making for WMS when testability, predictability, and explanatory potential are the criteria, I do take issue with the criteria and how they are shaped. However, we can always come back to this as I am further preoccupied by the underlying message that you believe that such valuation can be 
done respectfully. Where I am unable to follow your argument is in your statement that denying a student's cultural knowledge the status of scientific equivalency can be done without disrespecting the student: morality and episteme go hand in hand.

$U$ : While I agree with you that ethics and knowing go hand in hand, I do not agree with the conclusion you reach through this association. Rather, I would argue that not engaging in such comparative work would be disrespectful to students. I am making this claim on the basis that within the relationship between ethics and knowledge, there is a moral imperative to treat learners as fully rational persons or, at very least, in the process of becoming fully rational. Being fully rational means being capable of distinguishing between justified beliefs and beliefs that are either unjustified or less justifiable. Hence, providing students opportunities to exercise such rationality is to respect their capacity as learners.

$C C$ : Granted, not treating students as capable of learning and providing opportunities for rich learning is highly problematic and disrespectful. However, being respectful of students and their ability to learn need not be at the expense of their cultural knowledges.

$U$ : I agree here. As I mentioned earlier, providing opportunities to exercise reason need not be culturally insensitive, nor is this what I am arguing for. To learn as to why certain accounts, such as WMS, are worthy of belief is not the same as imposing knowledge or requiring the student to renounce their cultural knowledge.

$C C$ : While we agree on not dichotomizing this issue, I believe that perhaps we are attributing different weights to the ethical valuation of respecting a student's capacity to learn and respecting the culturally-specific scientific knowledge they bring with them into the classroom. I am not certain to which extent changing the explicit instructional message changes the implicit curricular one. As I do not see us moving forward on this at this point in time, let us return to our earlier discussion about science, education, and by extension, science education as situated learning processes. If we consider science, and hence science education, to be a situated practice, could we not include culture to the ways in which WMS' knowledge is constructed?

$U$ : As I have stated earlier, I do not deny the situatedness of scientific knowledge processes, nor do I deny that culture shapes scientific knowledge. As Siegel (2001) states, there is often a misconception that universalists are perceived as framing science as acultural and, accordingly, deniers of social constructivism. Rather, 
universalists happily agree that scientific theories are human constructions in the sense that they are conceived, formulated, articulated, and revised by human scientists... [They] agree that culture influences the truth claims - i.e., what is claimed at a time by scientists to be true - of science. (p. 807)

$C C$ : Then let us reframe an aspect of this conversation. I am going to ask you to reconsider the status that WMS is granted above other ways of knowing the natural world. If we consider this to be a cultural claim, would you agree that the privileging of WMS would then be considered culturally insensitive for those who do not belong to this culture?

$U$ : If this were strictly a cultural claim, I would have to agree, but this is certainly not the case. The privileging of WMS over other forms of understanding the natural world is not rooted in cultural presumptions or values, but rather on the criteria of "quality science": testable, predictive, and explanatory scientific theories.

$C C$ : Surely these criteria concerning what is considered "quality science" must also have their own cultural origins as well, mustn't they?

$U$ : Yes, they would. ${ }^{19}$ However, the fact that an idea has particular cultural origins need not mean that it is true or relevant only to or within that culture.

$C C$ : My concern here is that criteria for what counts as "quality science" are the same as those that define WMS. Furthermore, they are defined through the same set of cultural values. This circularity would lead me to believe, with WMS as the meter stick, that no other science could be considered "quality science" by virtue of it not being WMS. Would these criteria then not be self-serving, and therefore culturally presumptive as well as assimilationist when they become the basis for a "respectful" multicultural science education?

$U: \ldots$ but the criteria for good science are "universal" in that they are universally applicable. By this I do not mean that WMS transcends culture. Rather, if we are to take an instrumentalist approach, it is the most reliable, reproducible, and productive knowledge about the natural world. As such, it is applicable above and beyond the cultural circumstances in which it originated. For the sake of argument, even if it wasn't, teaching WMS need not be a form of cultural imperialism. It can be taught in a manner that is culturally respectful and sensitive, there can be science education without scientism.

$C C$ : Both of these clauses are debatable. While I believe that I have already addressed the first when I brought up the circularity of the argument, I am more concerned with the second. It has been argued that regardless of how culturally relevant, culturally responsive or culturally respectful 
science education is, if the end goal is to teach youth of WMS and bring them into its culture, it continues to be an assimilationist, marginalizing practice. Like Ali Sammel (2009),

I wonder if there is a science curricula that does not indoctrinate., $\ldots$ given the pervasiveness of assimilationism in Western science education... The system is pushing for assimilation of students into Western science ontology.... The structural inequities are given little attention while the mantra of we all have a chance to succeed in science reigns supreme. (p. 653, emphasis in original)

It may very well be that if, as science educators, we wish to reach our earlier agreed upon goal of "providing equitable opportunities for culturally diverse students", we may need to do so partially at the expense of what has traditionally and singularly been considered as "quality science".

$U$ : On this, we will have to agree to disagree. Like Charbel Niño El-Hani and Eduardo Fleury Mortimer (2007), I find myself asking:

How can we avoid demanding that our students change their beliefs by learning science, and, yet, intend that they apply in their lives what they learn in the science classroom? Surely, we could give up the second intention. But then why should we bother about teaching science at all? (p. 673)

If we need to take the "science" out of science education, then I will have no part of it. I think we are done here for today.

\section{Act 4: Playing Out The (Re)Production of KNOWLEDge}

\section{When (Re)Signifying Is Signifying Again Rather Than Anew}

Like all Socratic dialogues, the above dialogue on multicultural science education produces some shared understandings but fails to reach a conclusion beyond an agreement to disagree. This disagreement is both vis-à-vis "what counts as science" as well as how one might respectfully engage multicultural science education in terms of curriculum and instruction. It could be said that this result is, in part, a function of the medium through which a mimetic production of these debates within the science education literature is filtered and inflected. Another factor is 
that the predominant message being presented by the literature is that the debate was and continues to be left unresolved and unresolvable. ${ }^{20}$ However, regardless of whether it is or is not resolvable, the Socratic dialogue implicitly acts as an invitation to engage and participate in the always already occurring play of (re)signification.

Above and beyond the dialogue between universalist and crossculturalist characters that occurs within the play, there is also a dialogue and/or a dialectic that occurs between the reader and the text. Should you have made meaning in common (i.e., dialogically) rather than made common (i.e., dialectically), you may have located creative junctures inbetween the two positions that rupture and open up both sedimented scripts. However, if as a reader, you interpret the perspectives as irreconcilable, this does not mean that you have not engaged in the play of (re)signification. Rather, it may mean that the act of signification that you engaged is one that (re)plays that which is already there. In other words, through your engagement in the play of (re)signification, you have either signified again rather than anew the meanings that were already there. Recall that unmooring meaning is neither an easy nor individual affair; the "you" who (re)signifies is not only you-the language we possess also possesses us-we inherit and are haunted by longstanding and lingering meanings within science education. The production of meaning is always already produced between the text and yourself, and as such, both you and the text are partially implicated in whether the meaning made was complicit and/or critical as a function of the relational flow of meaning (Derrida, 1976; Lather, 2007; Mazzei, 2007; Spivak, 1976). ${ }^{21}$

Should you find yourself in the former position (i.e., complicit) rather than the latter (i.e., critical), it is worth considering a few key differences between the Adversary method and Socratic dialogue. While both methods rely on refuting arguments by shaking up beliefs that are held, the way they go about it and the purpose is different. Moulton (1983) elaborates that whereas the purpose of the Adversary method is to achieve epistemic victory, the goal of engagement in Socratic dialogue is to position the other party such that "they can begin philosophical inquiries with a more open mind" (p. 156). Furthermore, the success of the Socratic method depends on persuading the other person whereas the success of the Adversary method depends “on showing [the other person's] views to be wrong to others" (p. 156). Accordingly, while the Adversary method might be an effective means of proving someone wrong, it certainly is not an effective means of getting someone to agree with you. 
Bohm (1996) elaborates upon this by stating that such a mode of address is a double(d) form of violence. First of all, this puts the recipient on the defensive:

The opinions that we are defending ... are not merely opinions, they are not merely assumptions; they assumptions with which we are identified which we are therefore defending, because it is as if we defending ourselves. (p. 39)

Secondly, this self-defense psychically prevents not only the reception of that which is being levied against you but also productive dialogical thought that would allow you to find common ground:

You cannot defend something without first thinking the defense. There are those thoughts which might question the thing you want to defend, and you've got to push them aside. That may readily involve self-deception - you will simply push aside a lot of things you would rather not accept by saying they are wrong, by distorting the issue, and so on. Thought defends its base assumptions against evidence that they may be wrong. (p. 12, emphasis in original)

Through this process, sensory, and affective indicators often precede reactive thought in the form of anger, frustration, a gut feeling, a clenched jaw, a change in heart rate, or other. However, as Bohm (1996) states, you don't always make the connection between your sensory-affective reaction, what occurred, and what you are thinking-it is incredibly common for those schooled with, in, or though Western modernity to fragment the thought from the thinker (and the mind from the body with/in the thinker) (see also Cajete, 1994, 2000). Accordingly, you use the feeling or the sensation to justify the thought, or inability thereof. In short, the Adversary method simply does not encourage others to consider that which is causing this violence, but rather a (p)re-entrenchment, a position from which defense might be possible. In turn, this makes for poor scholarly engagement if engagement is defined as something more than an individualistic endeavour.

Instead, Socratic dialogue "looks for premises that the other person will accept and that will show that the original belief was false" (Moulton, 1983 , p. 156). It is certainly worth noting here that what each and every reader might need to be convinced will be different, as well as what they might be convinced of. Similarly, but holding patterns of difference, 
Bohmian dialogue searches for shared meanings. This does so by asking the question "is it absolutely necessary?" (Bohm, 1996, p. 26): is it absolutely required that the other be wrong or that there be an absolute truth? For Bohm (1996), "dialogue may not be concerned directly with the truth-it may arrive at truth, but it is concerned with meaning" (p. 43, emphasis in original). ${ }^{22}$ Such meaning is the type of shared meaning that emerges when assumptions and opinions are collectively opened and the play of (re)signification can occur without the need to negate previously held beliefs. Within recent literature, there have been some scholars who have been attempting to produce intermediary positions within the within the multicultural science education debate that extend (potential) points of agreement without negating firmly held claims. These dialogical possibilities yield potential for Indigenous science to-come (and are pulled through as productive insights for (re)opening the structures of science education in upcoming chapters).

\section{What Continues to (Not) Be at Play? Possibilities for Further Dialogue Through the Play of (Re)Signification}

As it stands, the debate continues within multicultural science education literature largely around conflicting notions of "quality science" (i.e., "what counts as science", how it is valued and evaluated) as well as questions of "quality education" (i.e., what is learned, how it is learned, questions of what constitutes respectful teaching and learning). However, a shared commitment across positions to a notion of science education that respects diverse knowers, as well as a commonly held view that it can be productive to include TEK and other non-WMS knowledges in the classroom exists, despite divergences on how these are conceptualized and enacted.

One such location is the growing consensus that students "should become scientifically literate, but not indoctrinated by scientism" (Zeyer, 2009, p. 1100). In other words, what in the past was primarily a cautionary note stemming from cross-culturalists (e.g., Lewis \& Aikenhead, 2001; Sammel, 2009; Snively \& Corsiglia, 2001; Stanley \& Brickhouse, 2001) is now general recognition of the possibility that science education can be and has been impositional in its nature. However, while Southerland (2000) states that one should not conflate of WMS's claim to universalism with the impositional nature of scientism, ${ }^{23}$ 
other universalists are increasingly taking the position that it is nonetheless a possibility, and one that all science educators (regardless of their positioning within the multicultural science education debate) should be actively working against (see also Cobern \& Loving, 2001, 2008; El-Hani \& de Ferreira Bandeira, 2008; El-Hani \& Mortimer, 2007; Zeyer, 2009).

Despite these gains for diversity and equity, there continues to be a multiplicity of sedimented and stuck categories and concepts that represent a serious challenge to dialogical interfacing of cross-culturalist and universalist positions. Accordingly, some science education scholars have welcomed the always already extended yet implicit invitation to engage in the play of (re)signification in order to labour these meaning-full disjunctures. They have opportunistically used shared yet never fully converging meanings (e.g., the goal of science $=/=$ scientism) to labour that which continues to (not) be at play (e.g., Cobern \& Loving, 2008; van Eick \& Roth, 2007; El-Hani \& Mortimer, 2007; McKinley \& Stewart, 2012). In other words, they look to that which is conceptually absent yet present (e.g., taken-for-granted implicit and tacit meanings) as a point of differential entry instead of (or in addition to) engaging in the dialectic negation of those with whom they would disagree. For example, and explored in further depth in Chapter 5, Cobern and Loving (2008) illuminate the absent presence of ontology within the multicultural science education debate in order to justify and defend a universalist position (in turn, denouncing cross-culturalism). With these absent presences, they inflect already present terms to mean something anew and askew.

Of particular interest is van Eijck and Roth's (2007) effort "to contribute to overcoming the multiculturalism-universalism incompatibility in science education" (p. 927) through the deconstruction of the theory/practice binary (i.e., theory as always already present within practice and vice versa). Specifically, they invite both universalists and crossculturalists to (mis)read knowledge as knowledge-practice. Drawing from cultural-historical activity theory and Bruno Latour's work of reading Louis Pasteur's discovery (of pasteurization) through Actor-Network Theory (Latour 1988), van Eijck and Roth (2007) extend a framework in which: (a) scientific knowledge derived through WMS is not only a product but also a dynamic and heterogeneous process; (b) never independent of human activity such that "there is no possibility for someone to 'have' knowledge and simultaneously 'fail to enact' it" (van Eijck \& Roth, 2007, p. 934); and (c) scientific knowledge is always in context such that it is both naturally and culturally situated (see also Alsop \& 
Fawcett, 2010; Barad, 2000, 2007; van Eijck \& Roth, 2009). They also signal the processual nature of scientific knowledge and the ways in it plays out in the production and application of the knowledge.

As presented in the play, both universalists and cross-culturalists agree that constructing reliable knowledge about the natural world, whether it be through WMS or TEK, is a process that is at once culturally mediated and employs naturalistic empiricism (Aikenhead \& Ogawa, 2007; Cobern \& Loving, 2001, 2008; Siegel, 1997, 2001; Snively \& Corsiglia, 2001). However, the processual quality of meaning-making with nature is often an absent presence that upholds arguments but does not fully come to bear on the culture of the multicultural science education debate. Importantly, (re)signifying knowledge as knowledge-practice does not require either party to renounce their position; rather, it potentially opens up fruitful locations for possible dialogue.

How might considering scientific knowledge as knowledge-practice assist us in collectively working towards the shared goal of working against scientism in science education? This is significant to the overall scope of this book as scientism often comes-to-be a central mechanism (alongside exclusivity and Eurocentrism; see McKinley \& Stewart, 2012) through which Indigenous science is excluded, differing, and deferred. The following are three contingent insights for potentially (re)opening the spaces of science education which will come to inform the work of the chapters to come, notably that scientific knowledge-practices are: (a) always situated (Chapter 4), (b) culturally hybrid (Chapter 7), and (c) ontologically situated (Chapters 5 and 6 ).

Scientific Knowledge-Practices as Always Situated. First, as van Eijck and Roth (2007) discuss, one salient example of such an opening produced by considering scientific knowledge as knowledge-practices is around the contested status of WMS as universal. Recall that for universalists, the knowledge produced by WMS is true in all contexts, with the cautionary note that it might not be the most appropriate form of knowledge when addressing particular topics and milieus (e.g., arts, social sciences, humanities, the super-natural; Cobern \& Loving, 2001, 2008; El-Hani \& de Ferreira Bandeira, 2008; El-Hani \& Mortimer, 2007; Zeyer, 2009). For cross-culturalists, what is at stake are the ways in which WMS is often granted epistemic privilege as a result of undiscerning translation into diverse contexts that supersedes longstanding, traditional, and complex knowledge-practices that are shaped in relation with the contexts in which they emerged (see Aikenhead \& Ogawa, 2007; Aikenhead \& 
Michell, 2011; Snively \& Corsiglia, 2001; Stanley \& Brickhouse, 2001). Van Eijck and Roth (2007) diverge from these either/or positions by focusing on the when and how of universal knowledge-practice, rather than the is or is not of universal knowledge (see also Harding, 2008). In short, they focus not only on the practice of developing knowledge that can be applicable in all contexts but also what it means to apply this knowledge in a wide range of contexts:

a twofold price must be paid for scientific knowledge to transcend local contexts and to become apparently static, singular, and homogeneous. First, for scientific knowledge to be produced and to be transcendent, the local contexts to be investigated must be reduced to scientific praxis. Second, for the scientific knowledge to be applied in another local context, this target context must be transformed again to scientific praxis. (van Eijck \& Roth, 2007, p. 938, emphasis in original)

In other words, they differentially articulate the cross-cultural statement that scientific knowledge-practices are decontextualized as well as the universalist one that scientific knowledge transcends context by firmly placing it within $a$ knowledge-practice context. This context, whether real or imagined, is the scientific laboratory:

the reduction of local contexts to scientific praxis is inherent to the static, homogeneous, singular, and transcendent nature of scientific knowledge and that transcendent scientific knowledge is useless unless local contexts are changed to function like scientific laboratories. (van Eijck \& Roth, 2007, p. 935)

While such conclusion may not necessarily be agreed upon by both sides as truth, it is nonetheless posits the possibility of shared meanings. For universalists, this does not require the abandonment of the notions that WMS is universal (i.e., applicable across multiple contexts) or "the best at what it does" (i.e., producing claims about nature). Treating the knowledge produced from empirical observation and Western modern scientific modes as if the context in which it was produced or applicable in were a scientific laboratory does not deny it of reliability or repeatability. Instead, it situates the conditions through which such a knowledge-practice is produced and applicable as well as the "price to be paid" for it to be so. For cross-culturalists, the situating of WMS as a knowledge-practice 
whose real or imagined context of production and applicability is the laboratory produces a space in which a localized TEK provides a welcome supplement to WMS that is more than the sum of what WMS is not. Because TEK is produced and producible through a knowledge tradition that accounts for and is accountable to the ecological contexts in which they are developed, TEK's knowledge-practices around nature are differentially produced with many of the exclusions that WMS must make to treat a context as a laboratory in mind. The "price to be paid" here is the difficulty in translating across diverse contexts. For the multicultural debate in science education here, this potentially produces a position in which the knowledge-practices of WMS and TEK might be able to share a differential yet overlapping space in which one can complement the other without the need to renounce one's position through the situating of one's knowledge-practice. ${ }^{24}$ These shared meanings might become ripe for a (re)opening of science education for Indigenous science to-come by not requiring an oppositional mode through which one side must emerge victorious.

Scientific Knowledge-Practices as Culturally Hybrid. The second possibility of working towards shared meanings with/in the multicultural science education by considering scientific knowledge as knowledgepractices debate rests in culturally hybrid knowledge-practices. Van Eijck and Roth (2009), continuing their earlier work, extend science's internal dynamism and heterogeneity outwards by considering the complex and conflicting ways in which WMS and TEK interact and interface at the level of the personal learner in pluralistic science education contexts. This is significant as discussions within multicultural science education debate are often framed by a Western/non-Western binary that disallows the play of (re)signification between the two. It is worth attending in brief to the primary problematics engendered by the production of a fallacious Western/non-Western binary including the exclusion of conversations around the hybridity of science and the complexities of these cultural interfaces (see also Harding, 2008). First, the assumption that cultural traits are either separate or that they can be separated that is produced by such a binary renders invisible the many elements of WMS that stem from non-Western cultural sciences and vice versa (e.g., the "father" of modern geometrical optics was Ibn al-Haytham, a middle-eastern a man). Secondly, as these contributions are not always recognized or brought up, the historical complexities of scientific knowledge production that occur at these cultural interfaces (e.g., appropriation, assimilation) are also, 
accordingly, left out (e.g., the Bayer pharmaceutical company's "discovery" and subsequent synthesis of traditional willow-bark-based medicine used by Indigenous peoples that is now known as Aspirin; see Snively \& Corsiglia, 2001). Lastly, the Western/non-Western binary makes it difficult for science educators to account for the complexities that occur at the currently lived and differently situated cultural interfaces that both they and their students occupy (see Belczewski, 2009; van Eijck \& Roth, 2009; Higgins, 2014). However, as this binary often operates within the bounds of multicultural science education, the Socratic dialogue is written in a way that reflects it. ${ }^{25}$ As Indigenous science's perpetual status of yetto-come is invariably shaped by culturally hybrid relations in which WMS and TEK are unevenly and unequally interfaced, considering this interface as a knowledge-practice entails that it is not something that simply is but rather something that is done. As a doing, this invites the possibility that it might be done otherwise, (re)opening this oft foreclosed space of science education towards the possibility of Indigenous science to-come.

Scientific Knowledge-Practices as Ontologically Situated. The third possibility for collectively working against scientism through situating scientific knowledge-practice lies in a consideration of ontology. Cobern and Loving (2008), extending van Eijck and Roth's (2007) notion that knowledge-practice is always culturally situated, direct attention to the ways in which epistemologies are always already ontologically situated. This is significant as the nature/culture binary, deployed within the context of the multicultural science education debate, disallows the play of (re)signification between the two (i.e., culture -> nature-culture; see also Barad, 2007; Latour, 1993). As Cobern and Loving (2008) suggest, the primary and almost exclusive focus on epistemologies within the debate has detracted from considerations of how epistemology aligns with ontology. ${ }^{26}$ While they use this (re)signified natural-cultural interplay to make a stronger case for universalism (e.g., "Epistemic Realism Really is Common Sense" [p. 425]), there is nonetheless room for the possibility of shared meanings. Taking seriously the notion that ontology is not a singular affair (Barad, 2007), this can be achieved not by refuting their claim but rather by situating it within $a$ context: epistemic realism (i.e., the epistemology of WMS) really does align best with an ontology of Cartesianism (i.e., the ontology of WMS). This creates a space in which WMS achieves "distinction not privilege" (Cobern \& Loving, 2008, p. 444) all the while not requiring universalists' claims of onto-epistemic alignment to be refuted. This also produces complimentary space for 
differently positioned, yet also onto-epistemologically aligned, forms of TEK (see Cajete, 1994, 1999, 2000). ${ }^{27}$ Such plurality without negation is significant for Indigenous science to-come as the requirement for there to be $a$ truth (read: singular) often places TEK at odds with WMS: a losing proposition when the norms of "what counts" as science best describes WMS (as "what counts" is modelled after WMS; see van Eijck \& Roth, 2007).

\section{Epilogue to (a) "Serious Play": A Call for Further Serious Play Through Dialogue}

The way in which the adversary method insidiously operates within the field of multicultural science education continues to produce a space which, by paying attention to extreme positions because they are extreme,

presents a distorted picture about what sorts of positions are worthy of attention, giving undo attention and publicity to positions merely because they are those of a hypothetical adversary's and possibly ignoring positions which make more valuable or interesting claims. (Moulton, 1983, p. 158)

The resulting entrenchment of positions leads to percussive and concussive discussions that foreclose the possibility of dialoguing across difference as well as the production of positions and positional propositions in-between those presented. Or, in my case within the example at the beginning of this text, the dramatic yet almost comedic mutual (dis)engagement protected our respective terms of engagement, prohibiting the possibility of productive conversation before it even began. Such engagements often result in communication that is protective and prohibitive rather than productive (Spivak, 1976).

While the Socratic dialogue within this chapter is meant to be but an imitation of life or a form of mimesis, this mimicry of a discussion between the educators holding universalist and cross-culturalist positions acts as an invitation to the possible play of (re)signification in order to make space for dialogue and the possibility of Indigenous science to-come. In turn, questions of respect within the multicultural science education classroom need to remain open to respond to the differentially entangled values, cultures, and histories of not only students present within the classroom, but also that of science, as well as peoples to whom a curricular geo-political commitment to is made (i.e., learning about and 
through local Indigenous peoples' ways-of-knowing-nature, regardless of classroom composition). Similarly, in order to keep the possibility of (re)signification of "what counts" as science open rather than foreclosed, there needs to be serious play with the assumption that non-Western bodies of scientific knowledge are not held as concurrent systems not because of their value, but how they are valued. As dialogue is about process and not product, "it's not all that important whether you agree or not... the point is that we would establish, on another level, a kind of bond" (Bohm, 1996, p. 37). It is important to not foreclose the possibility of shared meanings (rather than "universal" truths) that are made together, and within science education, this making in common need not necessarily exclude students, both Indigenous and non-Indigenous (see van Eijck \& Roth, 2009; Higgins, 2011). This is of utmost importance as not reaching shared meanings within the multicultural science education debate is of consequence for Indigenous science to-come as it upholds a status quo which (re)produces WMS as "what counts" best as science. ${ }^{28}$

While the multicultural science education debate is characterized by an agreement to disagree, this is not to say that the dialogical movement of meaning has not occurred. At the very least, there is an invitation to enact science education in a way that is less "caught in the competition of whose sword is sharper" (Spivak, 1994, p. 35). On this, it is important to recognize that the nature of the debate has changed by "accepting that all systems of knowledge about nature are embedded in the context of a cultural group; that all systems are, therefore culture-laden; and that (Western) science is the system of knowledge about nature that is predominant in Western culture" (Lewis \& Aikenhead, 2001, p. 3) and that even the strongest of universalists agree that multicultural science education is the direction that we should be taking in order for all students to benefit from science education. Furthermore, the three insights generated through (re)considering scientific knowledge as knowledge-practices (i.e., as always situated, as culturally hybrid, and as ontologically situated) will come to inform the work in the upcoming chapters as means of (re)opening science education towards Indigenous science to-come: creating possible possibilities for unsettling science education. However, there continues to be a need for the (re)opening of foreclosed meaningmaking spaces between and across scripted positions: what counts as science within science education continues to be a necessary and significant conceptual scene for dialogical engagement, as well as a productive rather than prohibitive point of entry for (further) serious play. 


\section{Notes}

1. Respecting Indigenous, diasporic, and other post-colonial students within the science education classroom is one of the key motivators within the culture of the multicultural science education debate for the inclusion of TEK. However, in classroom practices, the central focus is often on achievement; more specifically an "achievement gap" (without coming to understand the norms under which uneven scholastic achievement comes to be produced and producible; see McKinley, 2007; McKinley \& Stewart, 2012). However, as I have addressed elsewhere (Higgins, 2011, 2014), the incorporation of TEK and IWLN within the science classroom is beneficial for all students.

2. The now mantra of beginning some-where and some-time is not only a troubling of the notion of "beginnings" in the question of Indigenous science in science education, but also a reminder that because we are always already within the question, we can begin in a multiplicity of spatial and temporal locations.

This even includes chapters within the larger narrative of science education that have been deemed closed, such as the multicultural science education debate. The call of placing this moment in the past may well be a move to render this debate one that is passed over (see Derrida, 1994/2006). Rather, because it has not yet, and perhaps never will be, resolved, its logics continue to haunt the ways in which we, as science educators, approach the question of Indigeneity within science education. For example, and most significantly, I encounter many of the arguments that are made within the literature in science teacher education courses when engaging students with how we might respond to and meaningfully include Indigenous science within school science practice. Unsettling, in its double(d) meaning, requires that we attend to such sedimented and stuck locations that continue to bear on the ways in which settler colonial logics are perpetuated within science education.

Further and related, even if the temporality of this "beginning" is one that (re)opens a past passed over, it also points towards an enfolded and slow practice of serious listening in the here-now (to this lingering critique of the past). For Kuokkanen (2007), "listening seriously means that the listener is able to go beyond the sort of benevolent imperialism that makes arrogant assumptions about the speaker and her background" (p. 82). Listening too quickly, as unpacked in the previous chapter, can become a form of "listening-as-benevolent-imperialism' - that is, listening through the dominant discourses and epistemes and therefore not hearing what is actually said" (p. 75); this has the unintended consequence of deferring a problematic past and (re)producing it in the present. Rather, a slow listening requires that the listener inhabits the lengthy duration of the 
critique. As Kuokkanen (2007) suggests, we must not move too quickly towards resolution as this "can remove the hegemonic listener from the present and in this way either remove that listener from the present critique or place the hegemonic subject outside of that critique" (p. 142). For example, the binary logics of Western modernity often equate inaction and irresponsibility; blinding the porous slippage that occurs in the ways action itself can (re)produce the very problem being responded to in a de/colonizing moment and movement (see Higgins, 2014).

3. It is generally agreed upon by science educators that perceptions of WMS are often partially (mis-)informed by particular stereotypical and monolothic images of scientists, as well as the notion that there is $a$ way to do scientists think (e.g., the scientific method; see Aikenhead, 2006). Nonetheless, there are still often similarities enacted across Western modern sciences with respect to beliefs about science held and enacted by many (but likely not all) scientists (see Aikenhead \& Ogawa, 2007; Aikenhead \& Michell, 2011). These include, but are not limited to:

- Nature is governed by laws that are quantifiable, generalizable, and predictable-hence-nature is knowable (or can and will be known in instances in which knowledge technology does not allow for the study of phenomena).

- Nature can be reproduced (for realists) or represented (for socioconstructionists) through scientific knowledge;

- The production of scientific knowledge is embedded within social contexts. However, "the rigour of [WMS] decreases subjectivity as much as possible" (Aikenhead \& Michell, 2011, p. 43, emphasis in original) to make knowledge claims (quasi-)objective;

- Because scientific knowledge reproduces or represents nature (the latter with as little social and subjective noise as possible), scientific data speaks for itself;

- Constructing knowledge about the natural world (i.e., scientific knowledge) is the purview of humans and is represented or reproduced upon a static and (recti-)linear space and time.

4. Traditional ecological knowledge (TEK) is a term used by biologists and ecologists that became prevalent in the 1980s that usually signals "experience acquired over thousands of years of direct human contact with the environment" (Snively \& Corsiglia, 2001, p. 11). TEK is often synonymous with terms such as ethnoscience, Indigenous or Native science, as well as Indigenous knowledge and Indigenous knowledge systems; of which, it has become the most prevalent in usage (McKinley \& Stewart, 2012). These other terms are often preferred because TEK, like WMS, is a concept that is often (mis-)understood as a result of prevalent, pervasive, and problematic understandings (see previous endnote). These include 
"tradition" being defined in opposition to civilization and contemporaneity, "ecological" being reducible to ecology as defined by modern biology, and "knowledge" as discrete and separate not being an adequate referent for the relational knowledge processes from which TEK stem (see Kim, Ashgar, \& Jordan, 2017). Such mis- and missed representations are often complicated by under-representation (Aikenhead \& Ogawa, 2007; Aikenhead \& Michell, 2011; Snively \& Corsglia, 2001).

Similarly to WMS, there are many forms of TEK that are as diverse as the longstanding Indigenous peoples' traditions from which these knowledges stem. TEK is not the binary opposite of WMS, however this is not to say that there are not significant differences between the two (Aikenhead \& Ogawa, 2007; Aikenhead \& Michell, 2011). However, there are often some beliefs about nature that are sometimes but not always shared:

- Reality is not dualistic (i.e., Cartesian) but rather monist. This entails that nature is not separate from culture, and that the physical and metaphysical are always already entangled. In turn, this entails that parts of Nature (i.e., the frequent purview of science) only make sense within and can never be separated from the whole of nature or reality. This whole can be referred to as an ecology of relationships or a "sense of place" (see Cajete, 1994, 2000).

- Knowledge of nature emerges through natural-cultural relationships with knowledge keepers who are either human (e.g., Elders) or other-than-human (e.g., plants).

- Relationships entail responsibility. Accordingly, since everything is interrelated, the ecology of relationships is sustained by responsibility.

- Nature, which includes space, time, and matter, is in constant flux and in a state of indeterminacy, whose indeterminacy and flux is dis/continuous (e.g., non-linear time). In turn, while nature is empirically observable, it is never fully knowable; ways-of-knowingnature must remain open and dynamic to ongoing patterns of difference.

- Models developed empirically across generations do not function as representations of nature but rather as flexible and adaptive pedagogical tools for coming-to-know nature and be relationally accountable to one's relationships.

5. McKinley and Stewart (2012) suggest that the topic of IWLN in school science is one "that has, in the past, been subsumed under wider concepts, such as multiculturalism, equity, and the like" (p. 541). However, as postcolonial scholars of science education, they do not dismiss the locations in which inclusion happens as solely problematic. Rather, they critically inhabit these spaces as a site of both possibility and problematics through 
what could be read as taking a deconstructive stance. Taking a deconstructive stance is to "persistently to critique a structure that one cannot not (wish to) inhabit" (Spivak, 1993/2009, p. 284) by critically inhabiting the practices (linguistic or otherwise) at hand that shape us while at once troubling them.

As Spivak (1976) suggests, the language we possess also possesses us; thus, too simply moving beyond is "to run the risk of forgetting the problem or believing it to be solved" (p. xv) by reproducing it elsewhere, albeit differently. Thus, while recognizing the language of multiculturalism in science as a problematic entry point to consider the inclusion of IWLN, it is nonetheless the predominant entry point into conversations of, as well as gatekeeping device for, Indigenous knowledges in the science classroom. In turn, I also use and trouble this language.

6. The occurrence and recognition of classrooms as multicultural is recent. As McKinley and Stewart (2012) state:

Solid decades of economic growth, and increased sensitivity to human rights, post-World War II, supported a steady improvement in education outcomes for [I]ndigenous students. As globalisation proceeded, teachers in Western countries faced classrooms of increasing cultural diversity, and anti-ethnocentrism was one aspect of the response, with teachers challenged to overcome their own deficit thinking. (p. 546)

7. This distinction is significant. For example, Cobern and Loving (2008) engage a similar representational mode (i.e., a conversation) with the explicit "intention... to present the critical arguments in common sense terms" (p. 438) and the implicit one of demonstrating that the terms of their opposition (e.g., cross-culturalism through relativism) are untenable. However, this opposition is one that is largely imagined: cross-culturalists often repeat that they are advocating for pluralism rather than relativism and that they too do not wish the latter (see McKinley, 2007; McKinley \& Stewart, 2012). Furthermore, as discussed further within this chapter, discussions whose aim are to emerge victorious, rather than to listen to one another, are pyrrhic indeed. These victories not only ring hollow following the defeat of an imagined opponent, but such combativeness does not generate new and shared meanings but works towards making meaning common by suturing over other meanings. As such, these engagements always already fail in their ability to produce common grounds from which to address the complex questions of multicultural science education: they (re)produce ideological divisions which take us 
away from the possibility of learning from one another and working towards shared goals (see Bohm, 1996; Latour, 2004a, 2004b).

8. Reminder (from Chapter 2), I use of "foreclosure" to signal instantiated pre-emergence of meaning. In other words, foreclosure signals the ways in which the language we possess sometimes appears as already fully formed, stable, and signifying an ontologically stable location; foreclosure as the semiotic locations which resist (re)opening due to their naturalization as closed before the fact (Spivak, 1999).

9. Possible possibilities is an expression used throughout the book meant to signal that not all possibilities are possible, nor equally possible. However, as possibility and impossibility forever vacillate, possible possibilities are always on the move (Barad, 2007). However, and importantly, not all possibilities are desired nor desirable.

10. While theories of dialogue as practice (e.g., Bohm, 1996) do not explicitly limit the number of participants involved within a dialogue to two, it implicitly groups them in and treats them as reversible communicative pairs (i.e., transmitter and receiver) in a manner similar to Socratic dialogue.

Further, note that, as Spivak (1994) states: "dialogue is, in fact, the accepted proper name of responsibility as exchange-of-responses, implicitly understood as the flow of propositions or constatations rather than responses from both sides" (p. 45). Dialogue as responsibility presents itself as a mode to be able to respond, or of response-ability, to Indigenous science to-come (see Little Bear, 1994; Parrry, 2008).

11. Alternately, the process and product of dialectic and dialogue can be unpacked as mathematical operators. Consider two competing premises, positions, or postulates: $A$ and $B$. When brought into proximal relation, the type of ethic of resolution (i.e., the operator $x$ ) shapes what is produced (i.e., the resultant side of the mathematical equation).

Ideally, for dialectic, this interaction resembles such:

$$
A \times B=C
$$

Here, $C$ is a third position or statement that would be a "best of both worlds" that is developed in an equitable mode of collaboration. However, due to always uneven relations of power, this ideal is almost never achieved or achievable. In instances in which the unevenness is more pronounced, the dialectic often bears closer resemblance the following:

$$
A \times B=A
$$

This is what is referred to as dialectic negation: the absorption and/or annulment of the other term (here, $B$ ). 
Some respond to this by articulating an ethic of incommensurability in which:

$$
A \times B=A+B
$$

This entails that the two positions do not, cannot, and/or should not enter a proximal relation of co-production.

Recognizing that relations of power are always already uneven and unequal from the get go, dialogue strives to reach shared meanings without requiring the annulment of either meanings:

$$
A \times B=A+A B+A
$$

This entails that both propositions or positions (i.e., $A$ and $B$ ) stand while also producing a shared meaning as the multiplicative cross-product of the two $(A B)$.

12. As Spivak (1976) suggests, such deconstructive play might offer "a way out of the closure of knowledge" (p. lxxvii). For further examples of deconstructive play in science education, see Carter (2005) and McKinley and Aikenhead (2005).

13. While I lean towards a cross-culturalist position, it is productive for me to 'occupy' a position that leans towards universalism, even if it may be difficult for me, in order to think in ways that are productive rather than protective and prohibitive (see Spivak, 1976).

14. This landmark is, notably, a symposium in the journal Science Education (volume 85, issue 1). Despite its age, it remains relevant and significant. As McKinley and Stewart (2012) suggest, that since the publication of this symposium, "we have not progressed far with our arguments" (p. 547).

15. As dialogical approaches are infrequent within science education, this following section is intended to provide insights into how one might engage in this process. Furthermore, as Bohm (1994) posits from his work with artists, science has much to learn about questions of aesthetics, affect, and emotion and their respective role in process of knowledge production (and reproduction):

Long before the scientist is aware of the details of a new idea, he [or she, or they] may 'feel' it stirring in him [or her] in ways that are difficult or impossible to verbalize. These feelings are like very deep and sensitive probes reaching into the unknown, while the intellect ultimately makes possible a more detailed perception of what these probes have come into contact with. Here, then, is a very fundamental relationship between science and arts, the latter must 
evidently must work in a similar way, except that the whole process culminates in a sensually perceptible work of art, rather than in an abstract theoretical insight into nature's structural process. (p. 46)

16. (Re)opening science educator as location is an important project in the (re)opening of science education towards Indigenous science to-come. This is because educators are important performative agents who do and undo science education's circulating constructs, categories, concepts (see Higgins, 2014).

17. As Aikenhead and Ogawa (2007) elaborate and specify:

The word rational does not signify a universalist rationality, but a rationality founded within the cultural context of use... Perceiving means both the process of constructing what is perceived to be reality through the participation of a group of people, and their resultant mental constructions of reality. (pp. 543-544, emphasis in original)

This is significant: there needs to be attention to the ways in which we differ and defer attempts at making meaning across difference by slipping back into conventional understandings of science education as we bring related but not identical concepts into the picture (see Chapter 5; McKinley, 2000; Sammel, 2009).

18. As Glen Aikenhead and Dean Elliot (2010) point out, the culture of school science potentially produces experiences of assimilation or acculturation rather than enculturation for the vast majority of students ( $90 \%$; see also McKinley, 2007). In other words, most students run the risk of experiencing science education as a form of dialectic negation rather than a dialogical encounter.

19. See Chapter 6 for more on the operationalization of the culture of Western modern science.

20. While it is not wholly agreed upon that the debate is unresolvable (e.g., Hansson, 2018), unresolvability remains nonetheless a productive feature of the multicultural science education debate: it always remains, to a certain degree, open to being otherwise (e.g., open to Indigenous science to-come). However, as knowledge is a performative enactment (e.g., Butler, 1993, 2005, 2010), this (albeit partial) openness is contingent upon continued engagement.

For Hansson (2018), the argument is made that the debate could be resolved if we could come to appreciate that "science builds on the age-old traditions of joint fact-finding that we can find in these [other] cultures" (p. 522). While not wholly in disagreement, I also understand this as 
coming-to-perceive $a$ location in which the homework of response-ability should be engaged in. As explored more fulsomely in the chapters to come (Chapter 6 particularly), there is a nexus of reasons in which the disjuncture between Western modern and traditional knowledges is sedimented and stuck: there are multiple systems and structures in place which work to operationalize this disjuncture in favour of the Western modern Self at the expense of its (constructed) Other (e.g., a teleology of progress). Without also addressing these systems and structures, there runs the risk of this becoming a de/colonizing move: (re)producing a settled status quo, albeit differently.

21. Meaning-making of, or rather with texts is always a relational affair. As Spivak (1976) provocatively posits, this goes beyond deciphering the (i.e., singular) meaning intended by the author as it never was or will be possible for a text (or for a reader or an author) to reach the status of identity (i.e., self-sameness):

two readings of the "same" book show an identity that can only be defined as a difference. The book is not repeatable in its "identity": each reading of the book produces a simulacrum of an "original" that is itself the mark of the shifting and unstable subject..., using and being used by a language that is also shifting and unstable. (p. xii)

In other words, readings are always temporary, transient, and contingent because there was never is a stable text to being with. Accordingly, readings are never singular either but rather multiplicity. This multiplicity emerges from the multiple relationships in flux that come to shape each and every reading.

22. The means of knowledge production never come to fully coincide with its ends. In other words, the pursuit of truth never (fully) produces truth (Derrida, 1976). Nonetheless, while truth is always already deconstructing, deconstruction "is not the exposure of an error, it is a vigilance about the fact that we are always obliged to produce the truth" (Spivak in Harasym, 1990, p. 46).

23. However, as later explored in Chapters 5 and 6 , universalism and scientism are not so easily disentangled. While the two should not be conflated as they are not one and the same, logics of not-the-same come to mask the workings of power without an exploration of the ways in which they express themselves through co-constitutive difference.

24. The insight of scientific knowledge-practice as always already situated will come to inform the work of the Chapter 4. As scientific knowledge claims do not mirror reality but rather are prismatic inflections 
of knowledge through a real or imagined laboratory, the next chapter (re)considers optical metaphors as a location for rethinking criticality in science education.

25. Scientific knowledge-practice as always already being hybrid informs Chapter 7. As the ways in which hybridity is always uneven and unequal through a dialectic relationship in which Indigenous ways-of-knowing-inbeing are dialectically subsumed, sublated, or sutured over, the work of Chapter 7 considers the ways in which responsibility is also shaped within this interface. In turn, this interface must be laboured as it shapes the ability to respond (see Kuokkanen, 2007).

26. Note: Cobern and Loving's (2008) criteria of aligning with ontology problematically treats ontology as a singular affair.

27. The insight of scientific knowledge-practice as always already being ontologically situated becomes a central notion in Chapter 5 (and extended in Chapter 6), in which Cobern and Loving's (2008) call for ontological-epistemological alignment is both used and troubled to consider Cartesianism as but one ontology among many.

28. The ways in which science, education, and science education have respectively operated through forms of cognitive imperialism which have had, and continue to have, real and often negative effects on Indigenous and other non-Western peoples (McKinley, 2007).

\section{REFERENCES}

Aikenhead, G. S. (2006). Science education for everyday life. London, ON: Althouse Press.

Aikenhead, G. S., \& Elliot, D. (2010). An emerging decolonizing science education in Canada. Canadian Journal of Science, Mathematics and Technology Education, 10(4), 321-338.

Aikenhead, G. S., \& Michell, H. (2011). Bridging cultures: Indigenous and scientific ways of knowing nature. Toronto, ON: Pearson Canada.

Aikenhead, G. S., \& Ogawa, M. (2007). Indigenous knowledge and science revisited. Cultural Studies of Science Education, 2(3), 539-591.

Alsop, S., \& Fawcett, L. (2010). After this nothing happened. Cultural Studies of Science Education, 5(4), 1027-1045.

Atwater, M. M., \& Riley, J. P. (1993). Multicultural science education: Perspectives, definitions, and research agenda. Science Education, 77(6), 661-668.

Barad, K. (2000). Reconceiving scientific literacy as agential literacy. In R. Reed \& S. Traweek (Eds.), Doing science + culture (pp. 221-258). New York, NY: Routledge.

Barad, K. (2007). Meeting the universe halfway: Quantum physics and the entanglement of matter and meaning. Durham, NC: Duke University Press. 
Belczewski, A. (2009). Decolonizing science education and the science teacher: A white teacher's perspective. Canadian Journal of Science Education, 9(3), 191-202.

Bohm, D. (1994). On creativity. New York, NY: Routledge.

Bohm, D. (1996). On dialogue. New York, NY: Routledge.

Butler, J. (1993). Bodies that matter: On the discursive limits of "sex". New York, NY: Routledge.

Butler, J. (2005). On giving an account of oneself. New York, NY: Fordham University Press.

Butler, J. (2010). Frames of war: When is life grievable? London, UK: Verso.

Cajete, G. (1994). Look to the mountain: An ecology of indigenous education. Durango, CO: Kivaki Press.

Cajete, G. (1999). Igniting the sparkle: An Indigenous science education model. Durango, CO: Kivaki Press.

Cajete, G. (2000). Native science: Natural laws of interdependence. Santa Fe, NM: Clear Light Books.

Carter, L. (2004). Thinking differently about cultural diversity: Using postcolonial theory to (re)read science education. Science Education, 88(6), 819-836.

Carter, L. (2005). A place for alternative readings: Can they be of use? Responding to comments on "Thinking differently about cultural diversity: Using postcolonial theory to (re)read science education". Science Education, 89(6), 913-919.

Cobern, W. W., \& Loving, C. C. (2001). Defining "science" in a multicultural world: Implications for science education. Science Education, 85, 50-67.

Cobern, W. W., \& Loving, C. C. (2008). An essay for educators: Epistemological realism really is common sense. Science \& Education, 17, 425-447.

Derrida, J. (1976). Of grammatology (G. C. Spivak, Trans.). Baltimore, MD: John Hopkins University Press.

Derrida, J. (1994/2006). Specters of Marx: The state of the debt, the work of mourning, of the new international (P. Kamuf, Trans.). New York, NY: Routledge.

El-Hani, C. N., \& de Ferreira Bandeira, F. P. S. (2008). Valuing Indigenous knowledge: To call it "science" will not help. Cultural Studies of Science Education, 3(3), 751-779.

El-Hani, C. N., \& Mortimer, E. F. (2007). Multicultural education, pragmatism, and the goals of science teaching. Cultural Studies of Science Education, 2(3), 657-702.

Foucault, M. (1997). The politics of truth. New York, NY: Semiotext(e).

Hansson, S. O. (2018). How to reconcile the multiculturalist and universalist approaches to science education. Cultural Studies of Science Education, 13(2), 517-523. 
Harasym, S. (1990). The post-colonial critic: Interviews, strategies, dialogues. New York, NY: Routledge.

Harding, S. (2008). Sciences from below: Feminisms, postcolonialities, and modernities. Durham, NC: Duke University Press.

Higgins, M. (2011). Finding points of resonance: Nunavut students' perceptions of science. In Education, 17(3), 17-37.

Higgins, M. (2014). De/colonizing pedagogy and pedagogue: Science education through participatory and reflexive videography. Canadian Journal of Science, Mathematics and Technology Education, 14(2), 154-171.

Kim, E. J. A., Asghar, A., \& Jordan, S. (2017). A critical review of traditional ecological knowledge (TEK) in science education. Canadian Journal of Science, Mathematics and Technology Education, 17(4), 258-270.

Kirby, V. (2011). Quantum anthropologies: Life at large. Durham, NC: Duke University Press.

Kuokkanen, R. J. (2007). Reshaping the university: Responsibility, Indigenous epistemes, and the logic of the gift. Vancouver, BC: UBC Press.

Lather, P. (2007). Getting lost: Feminist efforts toward a double(d) science. New York, NY: State University of New York.

Latour, B. (1988). The pasteurization of France (A. Sheridan \& J. Law, Trans.). Cambridge, MA: Harvard University Press.

Latour, B. (1993). We have never been modern. Cambridge, MA: Harvard University Press.

Latour, B. (2004a). Why has critique run out of steam? From matters of fact to matters of concern. Critical Inquiry, 30(2), 225-248.

Latour, B. (2004b). Politics of nature: How to bring the sciences into democracy. Cambridge, MA: Harvard University Press.

Le Grange, L., \& Aikenhead, G. (2016). Rethinking the 'Western tradition': A response to Enslin and Horsthemke. Educational Philosophy and Theory, 1-7. Advance online publication. https://doi.org/10.1080/00131857.2016.116 7656.

Lewis, B., \& Aikenhead, G. (2001). Introduction: Shifting perspectives from universalism to cross-culturalism. Science Education, 85, 3-5.

Little Bear, L. (1994). Preface to Routledge classics edition. In D. Bohm (Ed.), Of creativity (pp. vii-xiv). New York, NY: Routledge.

Matthews, M. R. (1994). Science teaching: The role of history and philosophy of science. New York, NY: Routledge.

Mazzei, L. (2007). Inhabited silence in qualitative research: Putting poststructural theory to work. New York, NY: Peter Lang.

McKinley, E. (2000). Cultural diversity: Masking power with innocence. Science Education, 85(1), 74-76. 
McKinley, E. (2007). Postcolonialism, Indigenous students, and science education. In S. K. Abell \& N. G. Lederman (Eds.), Handbook of research on science education (pp. 199-226). Mahwah, NJ: Lawrence Erlbaum.

McKinley, E., \& Aikenhead, G. (2005). Comments on "Thinking differently about cultural diversity: Using postcolonial theory to (re)read science education". Science Education, 89(6), 901-906.

McKinley, E., \& Stewart, G. (2012). Out of place: Indigenous knowledge in the science curriculum. In B. Fraser, K. Tobin, \& C. J. McRobbie (Eds.), Second international handbook of science education (pp. 541-554). Dordrecht, NL: Springer, Netherlands.

Moulton, J. (1983). A paradigm of philosophy: The adversary method. In S. Harding \& M. B. Hintikka (Eds.), Discovering reality: Feminist perspectives on epistemology, metaphysics, methodology, and philosophy of science (pp. 149-164). Dordrecht, NL: Reidel.

Ogawa, M. (1995). Science education in a multiscience perspective. Science Education, 79, 583-593.

Parry, G. A. (2008). Seed graduate institute: An original model of transdisciplinary education informed by Indigenous ways of knowing and dialogue. Unpublished doctoral dissertation, California Institute of Integral Studies, Purdue University, San Francisco, CA.

Peat, F. D. (2007). Pathways of chance. Pari, IT: Pari Publishing.

Sammel, A. (2009). Turning the focus from 'other' to science education: Exploring the invisibility of whiteness. Cultural Studies of Science Education, 4, 649-656.

Siegel, H. (1997). Science education: Multicultural and universal. Interchange, $28,97-108$.

Siegel, H. (2001). Multiculturalism, universalism, and science education: In search of common ground. Science Education, 86, 803-820.

Smith, R. (2011). The play of Socratic dialogue. Journal of Philosophy of Education, 45(2), 221-233.

Snively, G., \& Corsiglia, J. (2001). Discovering Indigenous science: Implications for science education. Science Education, 85, 6-34.

Southerland, S. A. (2000). Epistemic universalism and the shortcomings of curricular multicultural science education. Science \& Education, 9, 289-307.

Spivak, G. C. (1976). Translator's preface. In J. Derrida (Ed.), Of grammatology (G. C. Spivak, Trans., pp. ix-lxxxvii). Baltimore, MD: Johns Hopkins University Press.

Spivak, G. C. (1993/2009). Outside in the teaching machine. New York, NY: Routledge.

Spivak, G. C. (1994). Responsibility. Boundary 2, 21(3), 19-64.

Spivak, G. C. (1999). A critique of postcolonial reason. Cambridge, MA: Harvard University Press. 
Stanley, W. B., \& Brickhouse, N. W. (1994). Multiculturalism, universalism, and science education. Science Education, 78, 387-398.

Stanley, W. B., \& Brickhouse, N. W. (2001). Teaching sciences: The multicultural question revisited. Science Education, 85, 35-49.

St. Pierre, E. A. (1997). Methodology in the fold and the irruption of transgressive data. International Journal of Qualitative Studies in Education, 10(2), 175-189.

Turnbull, W., \& Mullins, P. (2007). Socratic dialogue as personal reflection. Reflective Practice: International and Multidisciplinary Perspectives, 8(1), 93108.

van Eijck, M., \& Roth, W. M. (2007). Keeping the local local: Recalibrating the status of science and traditional ecological knowledge (TEK) in education. Science Education, 91(6), 926-947.

van Eijck, M., \& Roth, W. M. (2009). Authentic science experiences as a vehicle to change students' orientations toward science and scientific career choices: Learning from the path followed by Brad. Cultural Studies of Science Education, 4(3), 611-638.

Zeyer, A. (2009). Public reason and teaching science in a multicultural world: A comment on Cobern and Loving: An essay for educators...in the light of John Rawls’ Political Philosophy. Science \& Education, 18(8), 1095-1100.

Open Access This chapter is licensed under the terms of the Creative Commons Attribution 4.0 International License (http://creativecommons.org/licenses/ by $/ 4.0 /)$, which permits use, sharing, adaptation, distribution and reproduction in any medium or format, as long as you give appropriate credit to the original author(s) and the source, provide a link to the Creative Commons license and indicate if changes were made.

The images or other third party material in this chapter are included in the chapter's Creative Commons license, unless indicated otherwise in a credit line to the material. If material is not included in the chapter's Creative Commons license and your intended use is not permitted by statutory regulation or exceeds the permitted use, you will need to obtain permission directly from the copyright holder.

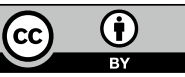

